Acta Crystallographica Section E

Structure Reports

Online

ISSN 1600-5368

R. S. Narasegowda,

S. M. Malathy Sony, ${ }^{b}$ S. Mondal,

B. Nagaraj, ${ }^{a}$ H. S. Yathirajan, ${ }^{a}$

T. Narasimhamurthy, ${ }^{\mathrm{c}}$

P. Charles,

M. N. Ponnuswamy, ${ }^{b}$

M. Nethaji ${ }^{d}$ and R. S. Rathore ${ }^{e_{*}}$

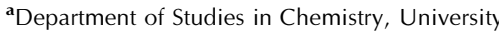
of Mysore, Manasagangotri, Mysore 570 006, India, ${ }^{\mathbf{b}}$ Department of Crystallography and Biophysics, University of Madras, Guindy Campus, Chennai 600 025, India,

${ }^{\mathbf{c}}$ Bioinformatics Centre, Indian Institute of

Science, Bangalore 560 012, India,

${ }^{\mathbf{d}}$ Department of Inorganic and Physical

Chemistry, Indian Institute of Science, Bangalore

560 012, India, and ${ }^{\mathbf{e}}$ Oriental Organisation of

Molecular and Structural Biology, 204 Agarwal

Bhavan, Malleshwaram, Bangalore 560055 ,

India

Correspondence e-mail:

ravindranath_rathore@yahoo.com

Key indicators

Single-crystal X-ray study

$T=292 \mathrm{~K}$

Mean $\sigma(\mathrm{C}-\mathrm{C})=0.003 \AA$

$R$ factor $=0.040$

$w R$ factor $=0.103$

Data-to-parameter ratio $=9.0$

For details of how these key indicators were automatically derived from the article, see http://journals.iucr.org/e.

\title{
2,2'-Diaminodibenzyl: a rare case of crystallo- graphically non-compliant molecular symmetry
}

The title compound, $\mathrm{C}_{14} \mathrm{H}_{16} \mathrm{~N}_{2}$, adopts a trans-planar conformation. However, the molecule, which possesses $C_{i}$ point group symmetry, crystallizes in the non-centrosymmetric space group $P 2{ }_{1} 2_{1} 2_{1}$. In the crystal structure, the molecular symmetry is only approximately retained. The crystal packing is predominantly stabilized by $\mathrm{N}-\mathrm{H} \cdots \mathrm{N}$ hydrogen bonds. Weak $\mathrm{C}-\mathrm{H} \cdots \pi$ interactions also contribute to the stability.

\section{Comment}

Investigations of the present structure were carried out independently by two groups, MNP (authors MNP, SMMS, PC and MN) and RSR (authors RSR, RSN, SM, BN, HSY and TN). Papers from the two groups were submitted to this journal within days of each other. Since the results of the two studies were very similar, the authors were requested to produce a joint paper. The amalgamated report is presented here.

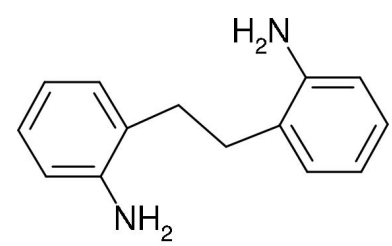

(I)

Among organic molecules there is a tendency for molecular symmetry to be retained in the crystal symmetry. Non-retention of molecular symmetry (i.e. complete lack of symmetry or the presence of non-crystallographic symmetry) is usually regarded as a consequence of dominant strong intermolecular forces. After seminal work by Kitaigorodskii (1961), which proposed that crystal symmetry is the outcome of the aim of achieving close-packed structures, many attempts have been made to correlate molecular and crystal symmetry (Yao et al., 2002, and references cited therein). Recent work (Pidcock et

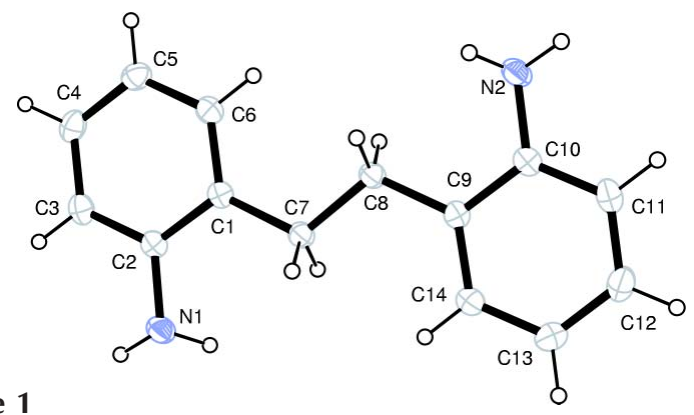

Figure 1

A view of (I), with the atom-numbering scheme. Displacement ellipsoids are drawn at the $30 \%$ probability level and $\mathrm{H}$ atoms are shown as small spheres of arbitrary radii. Color key: $\mathrm{C}$ black, $\mathrm{H}$ white and $\mathrm{N}$ blue.
Received 15 February 2005 Accepted 24 February 2005 Online 4 March 2005
(C) 2005 International Union of Crystallography Printed in Great Britain - all rights reserved 


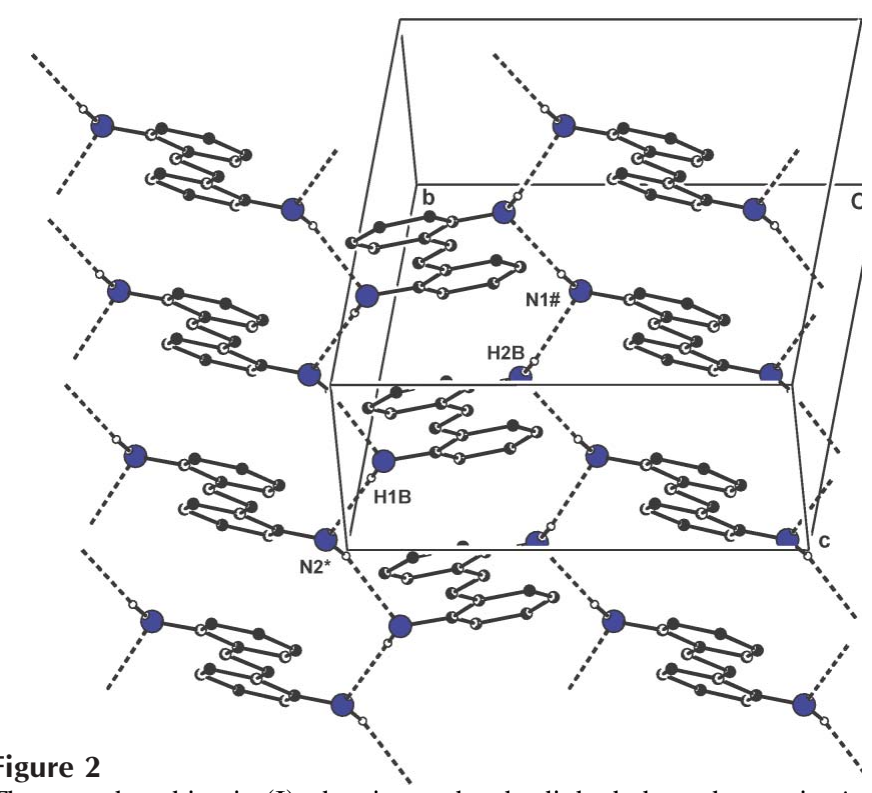

The crystal packing in (I), showing molecules linked along the $a$ axis via $\mathrm{N}-\mathrm{H} \cdots \mathrm{N}$ hydrogen bonds (dashed lines). Atoms labelled with an asterisk (*) or hash symbol (\#) are at the symmetry positions $\left(-x, y+\frac{1}{2}\right.$, $\left.\frac{3}{2}-z\right)$ and $\left(1-x, y-\frac{1}{2}, \frac{3}{2}-z\right)$, respectively. Color key: $\mathrm{C}$ black, $\mathrm{H}$ white and $\mathrm{N}$ blue.

al., 2003) has led to the conclusion that the inversion centre $\left(C_{i}\right.$ point group symmetry) is conserved in over $99 \%$ of cases. Higher molecular symmetries are retained in the crystal structure to a lesser extent. The present example of 2,2'diaminodibenzyl, (I), which possesses an inversion centre at the mid-point of the ethylene bridge, is a case where the molecular symmetry is only approximately conserved as pseudosymmetry in the noncentrosymmetric space group, $P 2_{1} 2_{1} 2_{1}$.

The title compound is an intermediate in the syntheses of the anticonvulsant and antidepressant drugs carbamazepine, imipramine and desipramine (Yathirajan et al., 2004).

The molecular structure of (I), which is planar, is shown in Fig. 1. Bond lengths and angles are unexceptional. The maximum deviation from the least-squares plane through all $\mathrm{C}, \mathrm{N}$ and aromatic $\mathrm{H}$ atoms is 0.05 (1) $\AA$ for atom N1. The N1 amino group is inclined at an angle of $49(1)^{\circ}$ to the C1-C6 ring, and the $\mathrm{N} 2$ amino group is inclined at $43(1)^{\circ}$ to the $\mathrm{C} 9$ C14 ring. A similar observation was also found in the related structure, 2,2'-dinitrodibenzyl (Yathirajan et al., 2004). The torsion angles describing the molecular conformation are as follows: $\mathrm{C} 2-\mathrm{C} 1-\mathrm{C} 7-\mathrm{C} 8=179.1(2)^{\circ}, \mathrm{C} 7-\mathrm{C} 8-\mathrm{C} 9-\mathrm{C} 10=$ $-179.6(1)^{\circ}, \mathrm{C} 1-\mathrm{C} 7-\mathrm{C} 8-\mathrm{C} 9=-179.6(2)^{\circ}, \mathrm{C} 9-\mathrm{C} 10-$ $\mathrm{N} 2-\mathrm{H} 2 A=39(2)^{\circ}, \mathrm{C} 1-\mathrm{C} 2-\mathrm{N} 1-\mathrm{H} 1 A=-43(2)^{\circ}, \mathrm{C} 9-$ $\mathrm{C} 10-\mathrm{N} 2-\mathrm{H} 2 B=168(2)^{\circ}$ and $\mathrm{C} 1-\mathrm{C} 2-\mathrm{N} 1-\mathrm{H} 1 B=$ $-168(2)^{\circ}$.

The r.m.s. deviation between all atoms related by the pseudo-inversion centre is $0.23 \AA$; if the $\mathrm{H}$ atoms attached to $\mathrm{N} 1$ and $\mathrm{N} 2$ are excluded this value is reduced to $0.02 \AA$. The maximum difference between corresponding torsion angles is $4^{\circ}$ for $\mathrm{C} 9-\mathrm{C} 10-\mathrm{N} 2-\mathrm{H} 2 A$ and $\mathrm{C} 1-\mathrm{C} 2-\mathrm{N} 1-\mathrm{H} 1 A$.

The geometric parameters for the intermolecular interactions in (I) are listed in Table 1. The crystal structure is

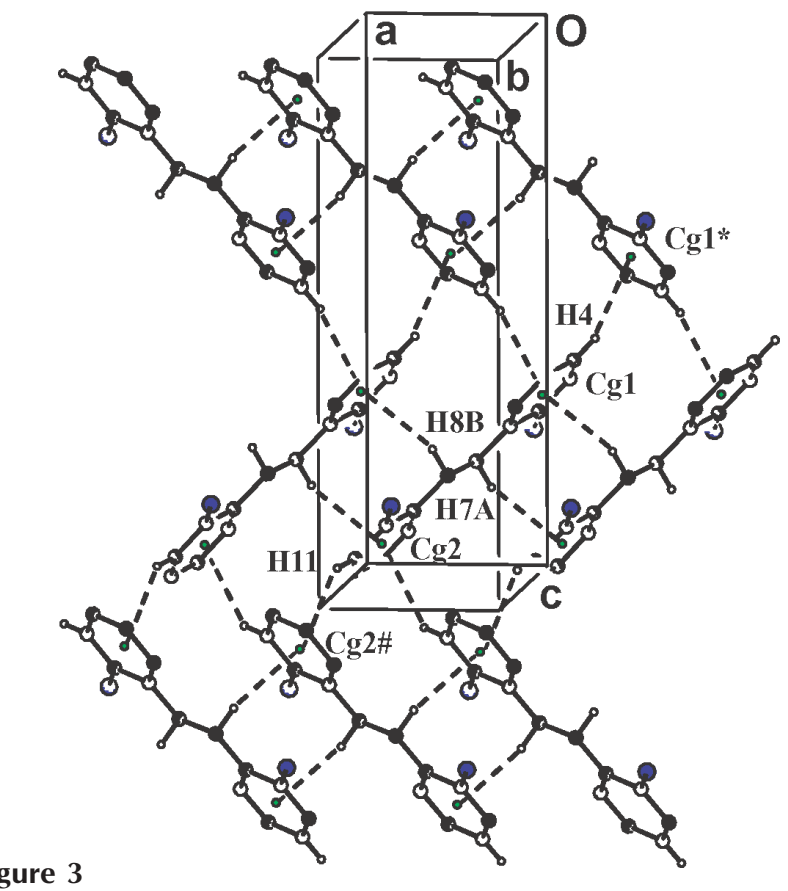

Figure 3

A view of the crystal packing in (I), showing molecules in the (040) plane, interconnected by $\mathrm{C}-\mathrm{H} \cdots \pi$ interactions (dashed lines). Atoms labelled with an asterisk $(*)$ or hash symbol (\#) are at the symmetry positions $\left(x-\frac{1}{2}, \frac{3}{2}-y, 1-z\right)$ and $\left(x+\frac{1}{2}, \frac{3}{2}-y, 2-z\right)$, respectively. $C g 1$ and $C g 2$ (shown in green) are the centroids of rings C1-C6 and C9-C14, respectively.

stabilized primarily by $\mathrm{N}-\mathrm{H} \cdots \mathrm{N}$ hydrogen bonds and weak $\mathrm{C}-\mathrm{H} \cdots \pi$ interactions. The hydrogen bonds $\mathrm{N} 1-\mathrm{H} 1 B \cdots \mathrm{N} 2$ and $\mathrm{N} 2-\mathrm{H} 2 B \cdots \mathrm{N} 1$ interlink molecules along the $a$ axis, as shown in Fig. 2. Atoms $\mathrm{C} 7$ and $\mathrm{C} 8$ of the ethylene bridge form $\mathrm{C}-\mathrm{H} \cdots \pi$ interactions with rings $\mathrm{C} 9-\mathrm{C} 14$ and $\mathrm{C} 1-\mathrm{C} 6$, on either side of the molecular plane. Significant $\mathrm{C}-\mathrm{H} \cdots \pi$ interactions are also observed for $\mathrm{C} 4-\mathrm{H} 4 \cdots C g 1(C g 1$ is the centroid of the $\mathrm{C} 1-\mathrm{C} 6$ ring $)$ and $\mathrm{C} 11-\mathrm{H} 11 \cdots C g 2(C g 2$ is the centroid of the $\mathrm{C} 9-\mathrm{C} 14$ ring) (Table 1). The aromatic interactions in the crystal structure are illustrated in Fig. 3.

We have examined the structures of similar compounds reported in the Cambridge Structural Database (CSD, Version 5.26; Allen, 2002). All 15 compounds containing the dibenzyl moiety and possessing $C_{i}$ point group symmetry have been reported in centrosymmetric space groups. For molecules possessing $C_{i}$ symmetry, crystallization in non-centrosymmetric space groups is very uncommon. In an examination of the CSDSymmetry database, a derived database of the CSD for molecular and crystallographic symmetry (Pidcock et al., 2003), out of 17893 available compounds possessing $C_{i}$ point group symmetry, 22 were found in the noncentrosymmetric space group $P 2_{1} 2_{1} 2_{1}$, which is generally favoured for molecules possessing $C_{2}$ point group symmetry (Yao et al., 2002). Inspection of these structures reveals that an overwhelming majority of them are metal-coordination compounds and involve a large number of strong intermolecular hydrogen bonds. They include, however, the case of $N, N, N^{\prime}, N^{\prime}$-tetramethyl-p-phenylenediamine (Ikemoto et al., 1979), where the crystal packing is governed purely by van der Waals forces. 


\section{Experimental}

The title compound was obtained from Max India Ltd. Crystals were grown by the slow-evaporation method, using both toluene and ethanol solvents. The data presented here correspond to a crystal obtained from toluene.

\section{Crystal data}

\section{$\mathrm{C}_{14} \mathrm{H}_{16} \mathrm{~N}_{2}$}

$M_{r}=212.29$

Orthorhombic, $P 2_{1} 2_{1} 2_{1}$

$a=5.4716$ (4) $\AA$

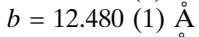

$c=16.695$ (1) $\AA$

$V=1140.0(2) \AA^{3}$

$Z=4$

$D_{x}=1.237 \mathrm{Mg} \mathrm{m}^{-3}$

Data collection

Bruker SMART CCD area-detector diffractometer

$\omega$ scans

Absorption correction: multi-scan (SADABS; Sheldrick, 1996)

$T_{\min }=0.97, T_{\max }=0.98$

9109 measured reflections

\section{Refinement}

Refinement on $F^{2}$

$R\left[F^{2}>2 \sigma\left(F^{2}\right)\right]=0.040$

$w R\left(F^{2}\right)=0.103$

$S=1.11$

1456 reflections

161 parameters

$\mathrm{H}$ atoms treated by a mixture of independent and constrained refinement

\section{Table 1}

Hydrogen-bond geometry $\left(\AA \mathrm{A}^{\circ}\right)$.

\begin{tabular}{lllll}
\hline$D-\mathrm{H} \cdots A$ & $D-\mathrm{H}$ & $\mathrm{H} \cdots A$ & $D \cdots A$ & $D-\mathrm{H} \cdots A$ \\
\hline $\mathrm{N} 1-\mathrm{H} 1 B \cdots \mathrm{N} 2^{\mathrm{i}}$ & $0.90(2)$ & $2.46(2)$ & $3.334(2)$ & $162(2)$ \\
$\mathrm{N} 2-\mathrm{H} 2 B \cdots \mathrm{N} 1^{\mathrm{ii}}$ & $0.88(2)$ & $2.45(2)$ & $3.255(2)$ & $153(2)$ \\
$\mathrm{C} 7-\mathrm{H} 7 A \cdots C g 2^{\mathrm{iii}}$ & 0.97 & 2.81 & $3.654(2)$ & 145 \\
$\mathrm{C} 8-\mathrm{H} 8 B \cdots C g 1^{\mathrm{iv}}$ & 0.97 & 2.78 & $3.624(2)$ & 147 \\
$\mathrm{C} 4-\mathrm{H} 4 \cdots C g 1^{\mathrm{v}}$ & 0.93 & 2.85 & $3.657(2)$ & 139 \\
$\mathrm{C} 11-\mathrm{H} 11 \cdots C g 2^{\text {vi }}$ & 0.93 & 2.92 & $3.678(2)$ & 139
\end{tabular}

Symmetry codes: (i) $-x, y+\frac{1}{2}, \frac{3}{2}-z$; (ii) $1-x, y-\frac{1}{2}, \frac{3}{2}-z$; (iii) $x-1, y, z$; (iv) $x+1, y, z$; (v) $x-\frac{1}{2}, \frac{3}{2}-y, 1-z$; (vi) $x+\frac{1}{2}, \frac{3}{2}-y, 2-z$. Cg1 is the centroid of the C1C6 ring and $C g 2$ is the centroid of the $\mathrm{C} 9-\mathrm{C} 14$ ring.
Mo $K \alpha$ radiation

Cell parameters from 5764 reflections

$\theta=5-54^{\circ}$

$\mu=0.07 \mathrm{~mm}^{-1}$

$T=292$ (2) K

Block, colourless

$0.51 \times 0.24 \times 0.15 \mathrm{~mm}$

1456 independent reflections 1344 reflections with $I>2 \sigma(I)$

$R_{\text {int }}=0.021$

$\theta_{\max }=27.4^{\circ}$

$h=-7 \rightarrow 6$

$k=-16 \rightarrow 14$

$w=1 /\left[\sigma^{2}\left(F_{\mathrm{o}}{ }^{2}\right)+(0.0596 P)^{2}\right.$ $+0.1255 P]$

where $P=\left(F_{\mathrm{o}}{ }^{2}+2 F_{\mathrm{c}}{ }^{2}\right) / 3$

$(\Delta / \sigma)_{\max }<0.001$

$\Delta \rho_{\max }=0.16{\mathrm{e} \AA^{-3}}^{-3}$

$\Delta \rho_{\min }=-0.28 \mathrm{e}^{-3}$

Extinction correction: none $l=-21 \rightarrow 21$

The aromatic and methylene $\mathrm{H}$ atoms were positioned geometrically and refined as riding on their carrier atoms, with $\mathrm{C}_{\mathrm{ar}}-\mathrm{H}=$ $0.93 \AA$, methylene $\mathrm{C}-\mathrm{H}=0.97 \AA$ and $U_{\text {iso }}(\mathrm{H})=1.2 U_{\text {eq }}(\mathrm{C})$. The $\mathrm{H}$ atoms attached to $\mathrm{N}$ were located in a difference electron-density map, and were refined isotropically; $\mathrm{N}-\mathrm{H}$ distances are in the range 0.88 (2)-0.91 (2) $\AA$. In the absence of significant anomalous dispersion effects, Friedel pairs were averaged.

Data collection: SMART (Bruker, 1998); cell refinement: SAINTPlus (Bruker, 2001); data reduction: SAINT-Plus; program(s) used to solve structure: SHELXS97 (Sheldrick, 1997); program(s) used to refine structure: SHELXL97 (Sheldrick, 1997); molecular graphics: ORTEP3 (Farrugia, 1997) and PLATON (Spek, 2003); software used to prepare material for publication: Win $G X$ (Farrugia, 1999) and PARST (Nardelli, 1995).

The authors thank Max India Ltd. for providing the sample and Professor T. N. Guru Row, SSCU, Indian Institute of Science, Bangalore, for providing the CCD facility. SMMS acknowledges the CSIR, India, for financial support.

\section{References}

Allen, F. H. (2002). Acta Cryst. B58, 380-388.

Bruker (1998). SMART. Version 5.054. Bruker, AXS Inc., Madison, Wisconsin, USA.

Bruker (2001). SAINT-Plus. Version 6.22. Bruker, AXS Inc., Madison, Wisconsin, USA.

Kitaigorodskii, A. I. (1961). Organic Chemical Crystallography. New York: Consultants Bureau.

Farrugia, L. J. (1997). J. Appl. Cryst. 30, 565.

Farrugia, L. J. (1999). J. Appl. Cryst. 32, 837-838.

Ikemoto, I., Katagiri, G., Nishimura, S., Yakushi, K. \& Kuroda, H. (1979). Acta Cryst. B35, 2264-2265.

Nardelli, M. J. (1995). J. Appl. Cryst. 28, 659.

Pidcock, E., Motherwell, W. D. S. \& Cole, J. C. (2003). Acta Cryst. B59, 634640.

Sheldrick, G. M. (1996). SADABS. University of Göttingen, Germany.

Sheldrick, G. M. (1997). SHELXS97 and SHELXL97. University of Göttingen, Germany.

Spek, A. L. (2003). J. Appl. Cryst. 36, 7-13.

Yao, J. W., Cole, J. C., Pidcock, E., Allen, F. H., Howard, J. A. K. \& Motherwell, W. D. S. (2002). Acta Cryst. B58, 640-646.

Yathirajan, H. S., Nagaraj, B., Nagaraja, P. \& Lynch, D. E. (2004). Acta Cryst. E60, o2455-o2456. 